\title{
Influence of $\alpha$-tocopherol on physicochemical properties of chitosan-based films
}

\author{
Joana T. Martins, Miguel A. Cerqueira, António A. Vicente* \\ IBB - Institute for Biotechnology and Bioengineering, Centre of Biological Engineering, Universidade do Minho, Campus de Gualtar, 4710-057 Braga, Portugal
}

\section{A $\begin{array}{llllllllll} & \text { T } & \text { I } & \text { C } & \text { L } & \text { E } & \text { I } & N & \text { F } & \text { O }\end{array}$}

\section{Article history:}

Received 28 March 2011

Accepted 25 June 2011

\section{Keywords:}

Chitosan

Biodegradable

Edible film

Antioxidant activity

Physical properties

\begin{abstract}
A B S T R A C T
Chitosan has been exploited as a material for the development of edible films, and additionally can be used as a carrier of functional compounds such as $\alpha$-tocopherol. The aim of this work was to evaluate the effects of the incorporation of $\alpha$-tocopherol in chitosan-based films. FTIR and thermal analyses were performed and showed that the incorporation of $\alpha$-tocopherol affects the chemical structure of chitosan-based films with the establishment of new chemical bonds and the decrease of crystallinity. Results also showed that the increase of $\alpha$-tocopherol concentration promotes a decrease of water content (from 12.6 to $11.4 \%$ ) of the films. The addition of $\alpha$-tocopherol to chitosan films leads to a significant reduction $(p<0.05)$ of tensile strength from 34.06 to $16.24 \mathrm{MPa}$, and elongation-at-break from 53.84 to $23.12 \%$. Film opacity values (ranging from 4.74 to $7.83 \%$ ) increased when $\alpha$-tocopherol was incorporated into the film. Antioxidant capacity of chitosan-based films was evaluated and was enhanced when $\alpha$-tocopherol was present in the film matrix. Results showed that $\alpha$-tocopherol can be successfully added to the chitosan films enhancing the final quality and shelf-life extension of food products.
\end{abstract}

(C) 2011 Elsevier Ltd. All rights reserved.

\section{Introduction}

The environmental impact of non-biodegradable plastic material wastes is of increasing global concern. There is an urgent need to develop renewable and environmentally friendly bio-based polymeric materials (Khwaldia, Arab-Tehrany, \& Desobry, 2010). Edible films can help solve the waste disposal problem by partially replacing non-biodegradable plastics. They can also act as a barrier to external influences such as water vapor, oil and oxygen, as a vehicle for functional compounds, and at the same time reducing e.g. bruising and breakage and thus preserving/improving food integrity.

Chitosan is a natural polymer obtained by deacetylation of chitin, and when compared with other polysaccharides, chitosan has several advantages such as biocompatibility, biodegradability and no toxicity, while also presenting functional properties as bacteriostatic and fungistatic (Dutta, Tripathi, Mehrotra, \& Dutta, 2009; Kumar, 2000). The cationic character of chitosan offers an opportunity to establish electrostatic interactions with other compounds. Due to these characteristics, chitosan has been widely used for the production of edible films (Aider, 2010; Rivero, García, \& Pinnoti, 2010; Ziani, Oses, Coma, \& Maté, 2008). Chitosan films present good barrier properties when compared with other polymers such

\footnotetext{
* Corresponding author. Tel.: +351 253604 419; fax: +351 253604429.

E-mail addresses: joanamartins@deb.uminho.pt (J.T. Martins), miguelcerqueira@ deb.uminho.pt (M.A. Cerqueira), avicente@deb.uminho.pt (A. A. Vicente).
}

as methylcellulose and corn starch (Debeaufort \& Voilley, 2009; García, Pinotti, Martino, \& Zaritzky, 2009). Also, mechanical properties of chitosan films can be improved e.g. by the addition of plasticizers (Yoshida, Junior, \& Franco, 2009); however, the presence of such compounds can affect the structure of chitosan films.

Recently, edible films and coatings appeared as an efficient vehicle for functional ingredients such as antioxidants, antimicrobials, nutrients, and flavors (Lin \& Zhao, 2007; Sánchez-González, Vargas, González-Martínez, Chiralt, \& Cháfer, 2009). Antioxidants can be incorporated into edible films in order to enhance food stability, functionality and safety and to control the oxidation of fatty components and pigments, contributing to food quality preservation (Lee, 2005). The incorporation of an antioxidant into chitosan-based films is an interesting way of extending chitosan-based films' functional properties. In fact, multifunctional packaging systems containing active substances have a high potential for commercial food packaging applications. Consumers prefer foods with improved safety; this is particularly relevant in the case of fresh and minimally processed food using this packaging system (Lee, 2005).

Lipid oxidation is one of the major processes occurring in food systems and has strong effects on development of off-flavors, color loss, bad odors and harmful compounds. The prevention of oxidation by addition of antioxidants is highly desirable in preserving fatty acids from oxidative deterioration. Vitamin $\mathrm{E}$ is an important antioxidant that can help reduce risk of diseases such as cardiovascular diseases and it is considered a GRAS compound (Strandberg $\&$ Albertsson, 2006). The lipophilic compound $\alpha$-tocopherol is the 
most abundant and biologically active form of vitamin E (Bramley et al., 2000) and is widely used in the pharmaceutical, food and cosmetic industries. Edible oils originating from plants, such as palm oil, sunflower oil, usually contain a large amount of $\alpha$-tocopherol (Kamal-Eldin \& Andersson, 1997). Due to its antioxidant properties and availability, $\boldsymbol{\alpha}$-tocopherol was chosen for this study. This natural antioxidant has been used in synthetic packaging materials such as low-density polyethylene to protect the packaged food from oxidative degradation (Koontz et al., 2010; Wessling, Nielsen, Leufvén, \& Jägerstad, 1999). Therefore, chitosan films containing an active antioxidant, such as $\alpha$-tocopherol, can be used as an active packaging system on food surface. In order to develop effective chitosan edible films with antioxidant activity, their physical, transport and mechanical properties should be assessed.

This work was carried out to understand the potential changes in transport, mechanical and thermal properties of chitosan-based films when $\alpha$-tocopherol was incorporated. The in vitro antioxidant capacity of the films with and without $\alpha$-tocopherol was also tested.

\section{Material and methods}

\subsection{Material}

$\alpha$-Tocopherol with $98 \%$ purity was supplied by Sigma-Aldrich (St. Louis, MO, USA). Chitosan was obtained from Golden-Shell Biochemical Co. Ltd. (China) with a degree of deacetylation of 95\%. Tween 80 (Acros Organics, Belgium); L(+)-lactic acid 90\% (Acros Organics, Belgium); and distilled water were used to prepare the film-forming solutions. DPPH radical scavenging assay was performed using 2,2-diphenyl-1-picrylhydrazyl (Sigma, Germany) and methanol P.A. (Riedel-de Haën, Germany).

\subsection{Preparation of edible films}

Chitosan-based films were prepared according to Souza et al. (2010) with some modifications. Film-forming solutions of chitosan were prepared dissolving $1.5 \%(\mathrm{w} / \mathrm{v})$ chitosan in a $1 \%(\mathrm{v} / \mathrm{v})$ lactic acid solution. For complete dissolution of chitosan, this solution was left for $8 \mathrm{~h}$ under agitation, using a magnetic stirrer, at room temperature $\left(20^{\circ} \mathrm{C}\right)$. Tween $80(0.1 \% \mathrm{w} / \mathrm{v})$ was added to the solution as a surfactant and as an emulsifier to assist $\alpha$-tocopherol dissolution in film-forming solutions. The solution was stirred for $20 \mathrm{~min}$ at $40^{\circ} \mathrm{C}$ for homogenization.

Films containing $\alpha$-tocopherol were prepared exactly as the control films however, after Tween 80 addition, $\alpha$-tocopherol was added to chitosan solution. Two different concentrations ( 0.1 and $0.2 \%(\mathrm{w} / \mathrm{v})$ ) were chosen based on preliminary experiments (data not shown) where it was determined that for $\alpha$-tocopherol concentrations above $0.2 \%$ the film would be too "greasy" on the surface. The obtained suspensions were homogenized with an Ultra-Turrax homogenizer ( $\mathrm{T} 25$, Ika-Werke, Germany) in 2 cycles, each of 2 min duration at $10,000 \mathrm{rpm}$.

To prepare the films, $30 \mathrm{~mL}$ of each solution were cast onto $90 \mathrm{~mm}$ Petri dishes and placed in an oven at $35^{\circ} \mathrm{C}$ for $16 \mathrm{~h}$; they were subsequently stored at $20^{\circ} \mathrm{C}$ and $54 \% \mathrm{RH}$, in a desiccator containing a saturated solution of $\mathrm{Mg}\left(\mathrm{NO}_{3}\right)_{2} \cdot 6 \mathrm{H}_{2} \mathrm{O}$, until further use.

\subsection{Fourier-transform infrared (FTIR) spectroscopy}

The IR spectra of the films were determined with an FT-IR spectrometer (Perkin-Elmer 16 PC spectrometer, Boston, USA), using Attenuated Total Reflectance (ATR) mode. Each spectrum results from 16 scans at $4 \mathrm{~cm}^{-1}$ resolution for a spectral range from $400-4000 \mathrm{~cm}^{-1}$. All the readings were performed at room temperature $\left(20^{\circ} \mathrm{C}\right)$. In the case of overlapping peaks, deconvolution was performed to calculate the contribution of the individual peaks using Peakfit software version 4.12 (SYSTAT Software, Richmond, CA). Deconvolution was used to estimate the area related to the specific vibration of the desired peak. Spectra of films were deconvoluted with a smoothing filter of $20 \%$. Each spectrum was baseline corrected and the absorbance was normalized between 0 and 1 .

\subsection{Thermal analyses}

The thermal stability and degradation profile of all chitosan film samples was assessed by thermogravimetric analysis (TGA) with a Shimadzu TGA 50 according to (Casariego et al., 2009). Film samples (approximately $5 \mathrm{mg}$ ) were put in high pressure stainless steel pans. An empty pan of the same type as the sample pan was used as a reference. Samples were heated at a constant rate of $10^{\circ} \mathrm{C} \mathrm{min}{ }^{-1}$ from 20 to $580^{\circ} \mathrm{C}$ in nitrogen atmosphere.

Differential scanning calorimetry (DSC) measurements were performed with a Shimadzu DSC-50 (Shimadzu Corporation, Kyoto, Japan) calibrated with Indium as standard. Ca. $10 \mathrm{mg}$ of the sample was placed in aluminum DSC pans (Al crimp Pan C.201-52943). The measurements were performed between 20 and $250{ }^{\circ} \mathrm{C}$ at a heating rate of $10^{\circ} \mathrm{C} \mathrm{min}^{-1}$ under a nitrogen atmosphere. Data were analyzed using TASYS software (Shimadzu Corporation, Kyoto, Japan).

\subsection{Thickness}

The film thickness was determined with a digital micrometer (No. 293-5, Mitutoyo, Japan). Five thickness measurements were randomly taken on each testing sample. The mean values were used to calculate water vapor permeability (WVP) and tensile strength (TS).

\subsection{Solubility and moisture content}

The film solubility in water was determined according to the method reported elsewhere (Casariego et al., 2009). The measurement of solubility of the films was determined as the percentage of soluble material after $24 \mathrm{~h}$ of immersion in water. To determine the moisture content of films about $50 \mathrm{mg}$ of film were dried at $105^{\circ} \mathrm{C}$ during $24 \mathrm{~h}$. The weight loss of the sample was determined, and the moisture content was calculated as the percentage of water removed from system. Three replicates were obtained for each sample.

\subsection{Water vapor permeability (WVP)}

The measurement of WVP was performed gravimetrically based on ASTM E96-92 method (Guillard, Broyart, Bonazzi, Guilbert, \& Gontard, 2003; McHugh, Avena-Bustillos, \& Krochta, 1993). The water transferred through the film and adsorbed by the desiccant (silica gel) was determined from weight loss of the permeation cell (cup containing distilled water at $100 \% \mathrm{RH} ; 2.337 \times 10^{3} \mathrm{~Pa}$ vapor pressure at $20^{\circ} \mathrm{C}$ ). The slope of weight loss versus time was obtained by linear regression. The measurement (WVP) of the films was determined as follows:

$W V P=(W V T R \times L) / \Delta P$

where WVTR is the water vapor transmission rate $\left(\mathrm{g} \mathrm{m}^{-2} \mathrm{~s}^{-1}\right)$ through the film, $L$ is the mean film thickness ( $\mathrm{m})$, and $\Delta P$ is the partial water vapor pressure difference (Pa) across the two sides of the film. For each type of film, WVP measurements were replicated three times.

\subsection{Tensile strength (TS) and elongation-at-break (EB)}

Mechanical properties were measured with an Instron Universal Testing Machine (Model 4500, Instron Corporation) following the 
guidelines of ASTM Standard Method D 882-91. The grip separation and crosshead speed were defined at $30 \mathrm{~mm}$ and $5 \mathrm{~mm} \mathrm{~min}^{-1}$, respectively. TS was expressed in $\mathrm{MPa}$ and $E B$ was expressed in percentage (\%). TS and $E B$ tests were replicated at least five times for each film.

\subsection{Color, opacity and light transmittance of the films}

The color of the films was determined with a Minolta colorimeter (CR 400; Minolta, Japan). A white color plate was used as a standard for calibration and as a background for color measurements of the films. $L^{*}, a^{*}, b^{*}$ values of each film were evaluated by reflectance measurements (Rao, Kanatt, Chawla, \& Sharma, 2010). The opacity of the samples was determined according to the Hunterlab method, as the relationship between the opacity of each sample on a black standard and the opacity of each sample on a white standard (Casariego et al., 2009).

The light transmission characteristics of the films were measured using a UV-Vis spectrophotometer Jasco V-560 (Tokyo, Japan). The percentages of light transmission were determined over the range 250-700 $\mathrm{nm}$ for each chitosan-based film (Jongjareonrak, Benjakul, Visessanguan, \& Tanaka, 2008). The measurements were repeated three times for each film.

\subsection{DPPH radical scavenging assay}

The radical scavenging activity of chitosan-based films was measured using the stable radical 2,2-diphenyl-1-picrylhydrazyl (DPPH) according to Byun, Kim, and Whiteside (2010). Briefly, approximately $100 \mathrm{mg}$ of film was placed in a flask containing $2 \mathrm{~mL}$ of methanol and was stirred for $3 \mathrm{~h}$ at room temperature $\left(20^{\circ} \mathrm{C}\right)$. The supernatant obtained was analyzed for DPPH radical scavenging activity. $2 \mathrm{~mL}$ of methanolic solution of DPPH $(0.06 \mathrm{mM})$ was mixed with $500 \mu \mathrm{L}$ of supernatant. The control was obtained using $500 \mu \mathrm{L}$ of methanol without the presence of the film. The mixture was vortexed vigorously and left for $30 \mathrm{~min}$ at room temperature in the dark. The remaining DPPH was determined by absorbance at $517 \mathrm{~nm}$ using a UV spectrometer (Varian-UV-Vis Spectrophotometer, Germany). The radical scavenging activity $(R S A)$ of the chitosan films was calculated according to the equation:

$\% R S A=100 \times\left(1-A_{\text {sample }} / A_{\text {control }}\right)$

where $A_{\text {sample }}$ represents the absorbance of the sample solution and $A_{\text {control }}$ represents the absorbance of DPPH solution without the addition of the film. All experiments were carried out in triplicate. The antioxidant capacity of chitosan-based films was expressed in \% DPPH radical scavenging activity/100 mg of film.

\subsection{Statistical analysis}

Statistical analysis was performed with software SigmaPlot 11.0 for Windows. One-way analysis of variance and Tukey's multiple comparisons test were performed to determine the significant differences. Significance was defined at a level of $p<0.05$.

\section{Results and discussion}

\subsection{Fourier-transform infrared (FTIR) spectroscopy}

The effect of $\alpha$-tocopherol in chitosan films was evaluated by FTIR analyses; when compounds are mixed, physical bonds and chemical interactions are reflected by changes in characteristic spectral peaks.

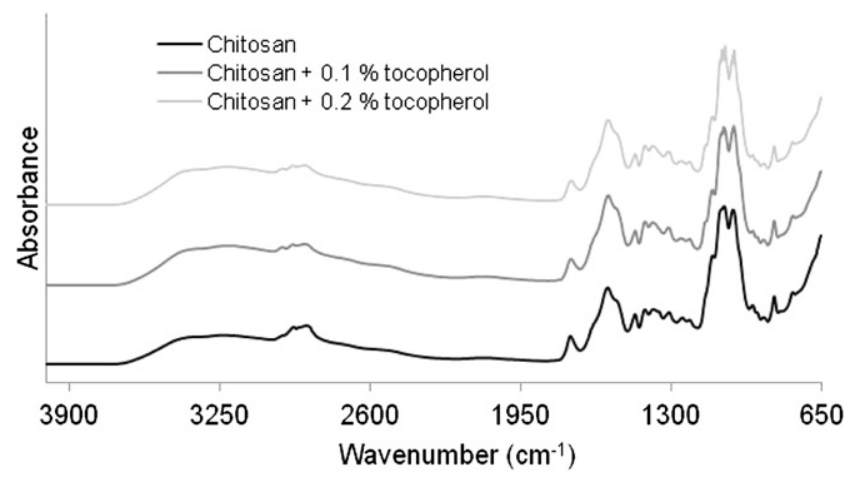

Fig. 1. FTIR spectra of the chitosan films for increasing $\alpha$-tocopherol concentrations.

Fig. 1 shows FTIR spectra of chitosan $(\mathrm{CH})$ films containing $0,0.1$ and $0.2 \%$ of $\alpha$-tocopherol (TOC). The broad band ranging between 3100 and $3500 \mathrm{~cm}^{-1}$ is attributed to $\mathrm{O}-\mathrm{H}$ stretching vibration that overlaps the $\mathrm{N}-\mathrm{H}$ stretching vibration in the same region. The broad band between 2800 and $3100 \mathrm{~cm}^{-1}$ is attributed to $\mathrm{C}-\mathrm{H}$ stretching vibration. The peak at $1557 \mathrm{~cm}^{-1}$ was due to the amide bending vibration $(\mathrm{N}-\mathrm{H})$, and the peak at $1733 \mathrm{~cm}^{-1}$ is characteristic of the presence of a carbonyl group $(\mathrm{C}=\mathrm{O})$ in the film matrix (Pawlak \& Mucha, 2003; Xu, Kim, Hanna, \& Nag, 2005; Ziani et al., 2008).

The deconvolution of the FTIR spectra was performed for two area bands: $800-1600 \mathrm{~cm}^{-1}$ and $2600-3600 \mathrm{~cm}^{-1}$, the corresponding peaks and areas are presented in Tables 1 and 2, respectively.

By deconvolution of the area band between 800 and $1600 \mathrm{~cm}^{-1}$, seven bands were observed for chitosan films with and without $\alpha$-tocopherol (Table 1 and Fig. 2). When $\alpha$-tocopherol is added to chitosan films a new peak (ca. $940 \mathrm{~cm}^{-1}$ ) appears that can be related with the $\mathrm{C}-\mathrm{O}$ vibrations of the alkoxyl group $(\mathrm{C}-\mathrm{O}-\mathrm{R})$ (Ning, Jiugao, Xiaofei, \& Ying, 2007).

Results showed a shift of the peak at $1026 \mathrm{~cm}^{-1}$ to 1019 and $1020 \mathrm{~cm}^{-1}$ for 0.1 and $0.2 \%$ of $\alpha$-tocopherol, respectively, ascribed to $\mathrm{C}-\mathrm{O}$ stretching of hydroxyl and ether bonds (Bu et al., 2010). Those bonds results from the presence of $\alpha$-tocopherol in the chitosan-based film matrix. A shift of the peak at $1088.7 \mathrm{~cm}^{-1}$ to peaks at 1074.8 and $1076.7 \mathrm{~cm}^{-1}$ was also observed with the increase of $\alpha$-tocopherol concentrations of $0.1 \%$ and $0.2 \%$, respectively. This shift has been related to the $\mathrm{C}-\mathrm{O}-\mathrm{H}$ bending (Jamróz et al., 2007). Both shifts (at 1026 and $1088.7 \mathrm{~cm}^{-1}$ ) may originate from a modification of the level of hydration of $\mathrm{C}-\mathrm{O}-\mathrm{H}$ groups, as previously suggested by Kačuráková and Mathlouthi (1996), which correlates well with the lower moisture content observed in chitosan films containing $\alpha$-tocopherol as described below in Section 3.3. Moisture content and solubility.

Table 1

List of FTIR peaks and fractional areas of bands between 800 and $1600 \mathrm{~cm}^{-1}$ for chitosan ( $\mathrm{CH}$ ) films for increasing $\alpha$-tocopherol (TOC) concentrations.

\begin{tabular}{|c|c|c|c|c|c|}
\hline \multicolumn{2}{|l|}{$1.5 \% \mathrm{CH}$} & \multicolumn{2}{|c|}{$1.5 \% \mathrm{CH}-0.1 \%$ TOC } & \multicolumn{2}{|c|}{$1.5 \% \mathrm{CH}-0.2 \%$ TOC } \\
\hline Peak $\left(\mathrm{cm}^{-1}\right)$ & Area (\%) & Peak $\left(\mathrm{cm}^{-1}\right)$ & Area (\%) & Peak $\left(\mathrm{cm}^{-1}\right)$ & Area (\%) \\
\hline 849.4 & $0.8=$ & $42.5 \pm 0.1$ & $5.7 \pm 0.2$ & $843.0 \pm 0.1$ & 5.7 \\
\hline $1026.6 \pm 2.7$ & $34.6=$ & $941.9 \pm 0.3$ & $4.1 \pm 0.1$ & $940.3 \pm 0.7$ & 0.1 \\
\hline $1088.7 \pm 4.8$ & $36.4 \pm 1.0$ & $1019.4 \pm 0.2$ & $29.5 \pm 0.4$ & $1020.1 \pm 0.8$ & $28.8 \pm 0.8$ \\
\hline $1310.0 \pm 5.0$ & $3.4 \pm 0.0$ & $1074.8 \pm 0.1$ & $30.3 \pm 0.8$ & $1076.6 \pm 1.0$ & $29.3 \pm 0.6$ \\
\hline $1382.7 \pm 1.6$ & $6.4 \pm 0.4$ & $1126.9 \pm 0.6$ & $8.9 \pm 0.3$ & $1131.0 \pm 0.6$ & $7.8 \pm 0.2$ \\
\hline \multirow[t]{3}{*}{$1447.1 \pm 1.4$} & $2.5 \pm 0.1$ & $1245.0 \pm 0.4$ & $0.7 \pm 0.1$ & $1241.9 \pm 0.0$ & $1.5 \pm 0.0$ \\
\hline & & $1319.1 \pm 0.4$ & $3.1 \pm 0.0$ & $1316.9 \pm 0.1$ & $3.6 \pm 0.0$ \\
\hline & & $1387.6 \pm 0.3$ & $5.4 \pm 0.0$ & $1384.8 \pm 0.0$ & $6.7 \pm 0.0$ \\
\hline
\end{tabular}


Table 2

List of FTIR peaks and fractional areas of bands between 2600 and $3600 \mathrm{~cm}^{-1}$ for chitosan (CH) films for increasing $\alpha$-tocopherol (TOC) concentrations.

\begin{tabular}{|c|c|c|c|c|c|}
\hline \multicolumn{2}{|l|}{$1.5 \% \mathrm{CH}$} & \multicolumn{2}{|c|}{$1.5 \% \mathrm{CH}-0.1 \% \mathrm{TOC}$} & \multicolumn{2}{|c|}{$1.5 \% \mathrm{CH}-0.2 \% \mathrm{TOC}$} \\
\hline Peak $\left(\mathrm{cm}^{-1}\right)$ & Area $(\%)$ & Peak $\left(\mathrm{cm}^{-1}\right)$ & Area (\%) & Peak $\left(\mathrm{cm}^{-1}\right)$ & Area (\%) \\
\hline $2714.4 \pm 1.6$ & $8.5 \pm 0.1$ & $2734.7 \pm 0.2$ & $6.9 \pm 0.0$ & $2734.9 \pm 0.0$ & $6.9 \pm 0.0$ \\
\hline $2899.2 \pm 0.6$ & $32.2 \pm 1.1$ & $2889.1 \pm 1.6$ & $19.0 \pm 0.2$ & $2890.9 \pm 0.0$ & $19.3 \pm 0.0$ \\
\hline $3107.5 \pm 1.2$ & $18.9 \pm 0.4$ & $3007.7 \pm 2.0$ & $11.1 \pm 0.3$ & $3009.9 \pm 0.2$ & $10.7 \pm 0.1$ \\
\hline $3260.3 \pm 1.5$ & $20.9 \pm 0.4$ & $3129.3 \pm 0.7$ & $16.7 \pm 0.0$ & $3130.1 \pm 0.0$ & $16.7 \pm 0.0$ \\
\hline \multirow[t]{3}{*}{$3418.8 \pm 1.4$} & $19.4 \pm 0.3$ & $3251.7 \pm 1.3$ & $19.3 \pm 0.1$ & $3253.3 \pm 0.0$ & $19.4 \pm 0.0$ \\
\hline & & $3385.3 \pm 3.4$ & $18.9 \pm 0.5$ & $3389.3 \pm 0.1$ & $19.5 \pm 0.0$ \\
\hline & & $3483.6 \pm 4.2$ & $8.1 \pm 0.5$ & $3488.5 \pm 0.1$ & $7.5 \pm 0.0$ \\
\hline
\end{tabular}

Still in the band region between 800 and $1600 \mathrm{~cm}^{-1}$, a new peak appears at ca. $1245 \mathrm{~cm}^{-1}$ when $\alpha$-tocopherol is added, which can be related to the bending vibration of the $\mathrm{OH}$ groups from the phenol group present in $\alpha$-tocopherol structure (Mart, Sökmen, \& Yürük, 2006). Once the phenol group is present only in the $\alpha$-tocopherol

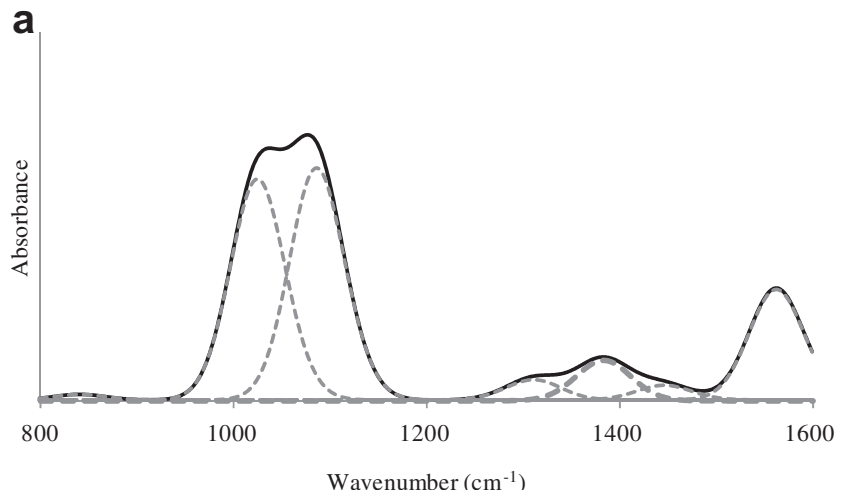

b
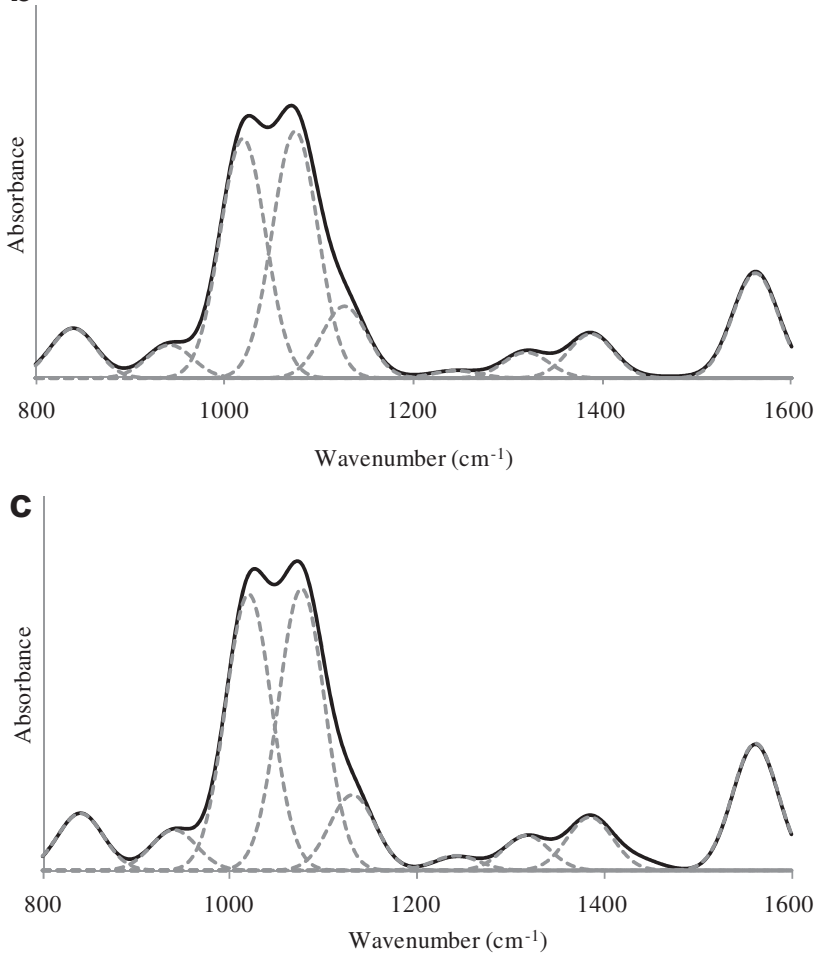

Fig. 2. FTIR deconvoluted spectrum in the range $800-1600 \mathrm{~cm}^{-1}$, corresponding to chitosan films with (a) $0 \%$, (b) $0.1 \%$ and (c) $0.2 \%$ of $\alpha$-tocopherol. molecules, the presence of this peak is a clear evidence of the incorporation of $\alpha$-tocopherol in the film matrix.

Table 2 and Fig. 3 show the deconvolution of area band between 2600 and $3600 \mathrm{~cm}^{-1}$ of FTIR spectra for chitosan films. In the range $2700-3000 \mathrm{~cm}^{-1}$, numerous bands were noted and attributed to the asymmetric and symmetric stretching vibrations of the $\mathrm{CH}_{2}$ and $\mathrm{CH}_{3}$ (Silva, Rosa, Ferreira, Boas, \& Bronze 2009; Xu et al., 2005). When $\alpha$-tocopherol is added to chitosan films a shift occurs in the peak at ca. $2714 \mathrm{~cm}^{-1}$ for ca. $2734 \mathrm{~cm}^{-1}$, with the decrease of the correspondent areas. The peak area at ca. $2899 \mathrm{~cm}^{-1}$ also suffers a change, decreasing from $32 \%$ to $19 \%$ when $\alpha$-tocopherol is added. It may be anticipated that these shifts may be related to changes in $\mathrm{CH}_{2}$ and $\mathrm{CH}_{3}$ groups vibrations, but at this point there are no scientific evidences available to support this hypothesis.

New peaks at ca. 3007 and $3009 \mathrm{~cm}^{-1}$ were observed for chitosan films with 0.1 and $0.2 \%$ of $\alpha$-tocopherol, respectively. These peaks are indicators of the increase of cis double-bond stretching vibration $(=\mathrm{CH})$ in the film samples (Vlachos et al., 2006) and have been reported as distinctive peaks of $\alpha$-tocopherol.
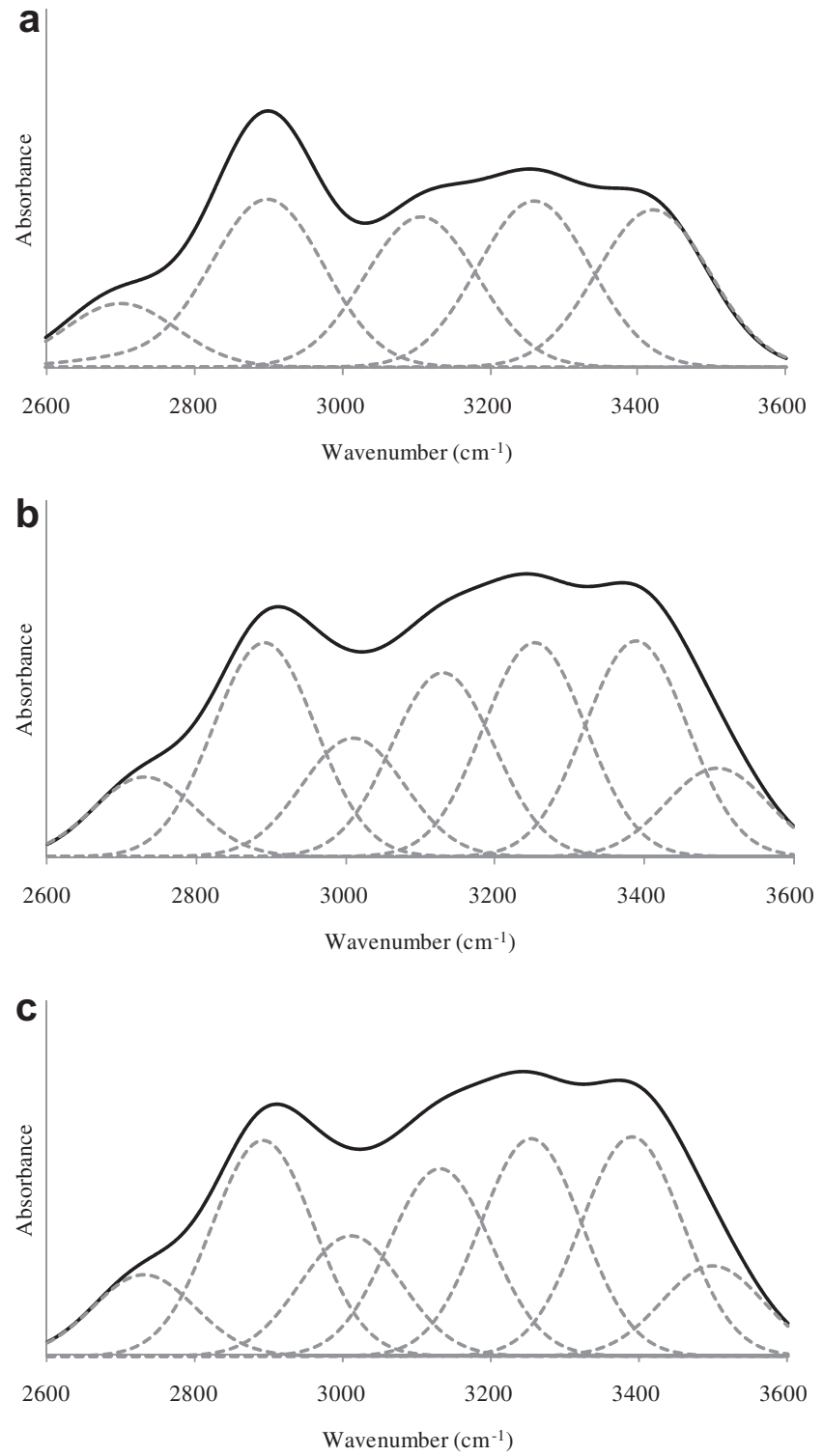

Fig. 3. FTIR deconvoluted spectrum in the range $2600-3600 \mathrm{~cm}^{-1}$, corresponding to chitosan films with (a) $0 \%$, (b) $0.1 \%$ and (c) $0.2 \%$ of $\alpha$-tocopherol. 
Table 3

Thermal behavior of chitosan (CH) films for increasing $\alpha$-tocopherol (TOC) concentrations. The values of the peaks correspond to the values of derivative thermograms obtained by the TGA curve.

\begin{tabular}{|c|c|c|c|c|c|}
\hline \multicolumn{2}{|l|}{$1.5 \% \mathrm{CH}$} & \multicolumn{2}{|c|}{$1.5 \% \mathrm{CH}-0.1 \% \mathrm{TOC}$} & \multicolumn{2}{|c|}{$1.5 \% \mathrm{CH}-0.2 \% \mathrm{TOC}$} \\
\hline $\begin{array}{l}\text { Peak } \\
\text { temperature } \\
\left({ }^{\circ} \mathrm{C}\right)\end{array}$ & $\begin{array}{l}\text { Weight } \\
\text { loss (\%) }\end{array}$ & $\begin{array}{l}\text { Peak } \\
\text { temperature } \\
\left({ }^{\circ} \mathrm{C}\right)\end{array}$ & $\begin{array}{l}\text { Weight } \\
\text { loss (\%) }\end{array}$ & $\begin{array}{l}\text { Peak } \\
\text { temperature } \\
\left({ }^{\circ} \mathrm{C}\right)\end{array}$ & $\begin{array}{l}\text { Weight } \\
\text { loss (\%) }\end{array}$ \\
\hline $101.9 \pm 1.9$ & $10.6 \pm 0.7$ & $107.4 \pm 8.9$ & $8.9 \pm 0.2$ & $104.4 \pm 19.9$ & $9.5 \pm 1.0$ \\
\hline $202.5 \pm 2.7$ & $11.2 \pm 0.6$ & $203.4 \pm 2.5$ & $12.5 \pm 0.6$ & $204.1 \pm 5.6$ & $13.1 \pm 0.9$ \\
\hline $291.2 \pm 2.8$ & $32.7 \pm 1.9$ & $292.7 \pm 2.4$ & $32.2 \pm 1.9$ & $295.3 \pm 2.5$ & $32.5 \pm 2.0$ \\
\hline & & $439.1 \pm 4.6$ & $6.3 \pm 1.3$ & $441.0 \pm 2.5$ & $8.6 \pm 0.7$ \\
\hline
\end{tabular}

The peak at ca. $3418 \mathrm{~cm}^{-1}$, characteristic of the inter- and intramolecular hydrogen bonding of hydroxyl groups (Cao, Shi, \& Chen, 1998) and stretching vibration of secondary amine groups $(\mathrm{N}-\mathrm{H})$ (Sun \& Wang, 2006), present in chitosan films spectra, shifts to 3385 and $3389 \mathrm{~cm}^{-1}$ with the addition of 0.1 and $0.2 \%$ of $\alpha$-tocopherol, respectively. In addition to the shift at $3418 \mathrm{~cm}^{-1}$, new peaks appeared near 3483 and $3488 \mathrm{~cm}^{-1}$ when 0.1 and $0.2 \%$ of $\alpha$-tocopherol were added to chitosan film, respectively; these peaks are assigned to $\alpha$-tocopherol hydrogen bonds (Luo, Zhang, Whent, Yu, \& Wang, 2011). These results point out that the main interaction between $\alpha$-tocopherol and chitosan would be through hydrogen bonds, as suggested by other authors (Prado et al., 2011).

\subsection{Thermal analysis}

Thermogravimetric analyses determine the changes in weight of the films samples with the increase of the temperature. Table 3 and Fig. 4 show the peak values and the corresponding weight loss for each event, for chitosan films. They present at least three thermal events; however for samples with $\alpha$-tocopherol a fourth event was observed. Peak 1 results from the evaporation process; this phenomenon could be related to the hydrophilic nature of the polysaccharide. Peak 2 (around $200^{\circ} \mathrm{C}$ ) is related to chemisorbed water through hydrogen bonds and the elimination reaction of $\mathrm{NH}_{3}$ (Quijada-Garrido, Iglesias-González, Mazón-Arechederra, \& Barrales-Rienda, 2007). However, no relevant differences in weight loss were observed between films with or without $\alpha$-tocopherol. Peak 3 (around $290^{\circ} \mathrm{C}$ ) is related with the dehydration, depolymerization and pyrolytic decomposition of the polysaccharide backbone (Zohuriaan \& Shokrolahi, 2004). Films containing $\alpha$-tocopherol showed a fourth peak (peak 4) associated with $\alpha$-tocopherol aromatic structures decomposition at temperatures above $380^{\circ} \mathrm{C}$ (Pelissari, Grossmann, Yamashita, \& Pineda, 2009). The $\alpha$-tocopherol addition had no influence on thermal stability of chitosan films as demonstrated by the small variation in peak temperatures of the above-mentioned thermal events (at ca. 200 and $290^{\circ} \mathrm{C}$ ).

Differential scanning calorimetry (DSC) analyses were used to measure the enthalpy of melting $\left(\Delta h_{m}\right)$ and the peak melting temperature $\left(T_{m}\right)$ of the films. $\Delta h_{m}$ and $T_{m}$ can be associated with the crystallinity of the film samples (Peesan, Supaphol, \& Rujiravanit, 2005; Sperling, 2006, chap. 6). Table 4 and Fig. 5 show that the incorporation of $\alpha$-tocopherol into chitosan films leads to the decrease $\Delta h_{m}$ and to the increase of $T_{m}$. The decrease of $\Delta h_{m}$ with the addition of $\alpha$-tocopherol can be associated with the decrease of the films crystallinity. It is known that chitosan films are semicrystalline (Ziani et al., 2008); $\alpha$-tocopherol incorporation reduces the relative amount of crystalline structures in the film, leading to a more amorphous structure (Sperling, 2006, chap. 6), which may be due to the interruption of the crystalline structure formation in the chitosan matrix (Park \& Zhao, 2004).
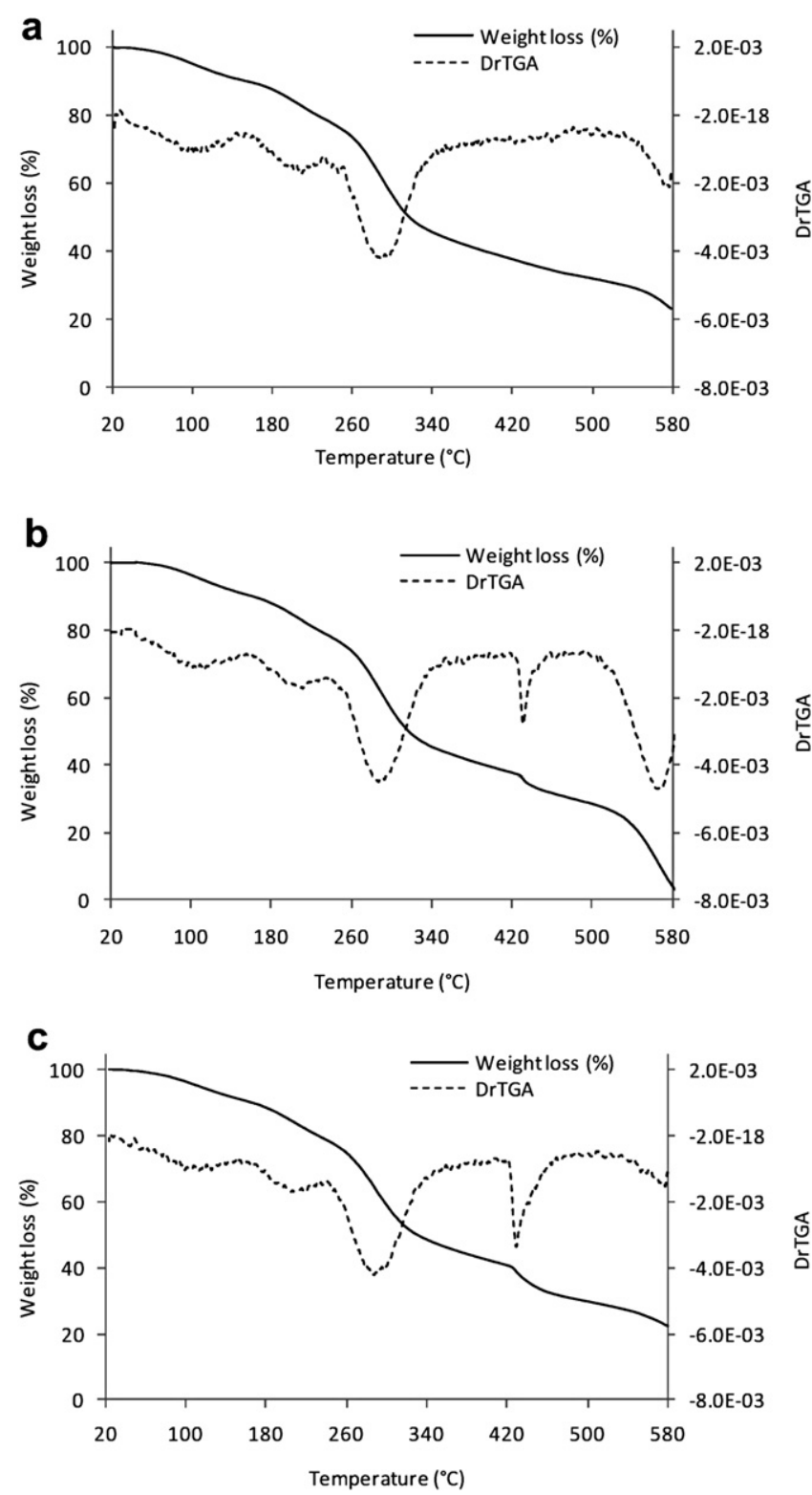

Fig. 4. TGA and DrTGA curves for chitosan films with (a) $0 \%$, (b) $0.1 \%$ and (c) $0.2 \%$ of $\alpha$-tocopherol.

\subsection{Moisture content and solubility}

Water sensitivity is one of the major problems of polysaccharide-based films, and is evaluated by different methods such as monitoring moisture content, water activity and sorption, solubility, contact angles and through the measurement of the water vapor permeability (Fabra, Talens, \& Chiralt, 2010; Ferreira, Nunes, Delgadillo, \& Lopes-da-Silva, 2009; Sánchez-González et al., 2009). Solubility of films in water may also provide insight on the behavior of a film in an aqueous environment and is a measure of its water resistance. This is also an important factor that determines biodegradability of films when used as packaging materials (Gnanasambadam, Hettiarachchy, \& Coleman, 1997). Table 4 shows the solubility and moisture content values obtained for chitosanbased films. The increase of $\alpha$-tocopherol concentrations $(0-0.2 \%)$ leads to a significant decrease $(p<0.05)$ of moisture content values due to the hydrophobic nature of $\alpha$-tocopherol. This observation is in agreement with the FTIR results; the change in the peak ascribed 
Table 4

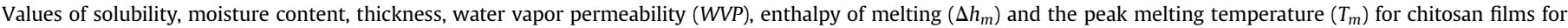
increasing $\alpha$-tocopherol concentrations.

\begin{tabular}{|c|c|c|c|c|c|c|}
\hline$\alpha$-Tocopherol & Solubility (\%) & Moisture content (\%) & Thickness (mm) & $W V P \times 10^{-11}\left(\mathrm{~g} \mathrm{~m}^{-1} \mathrm{~s}^{-1} \mathrm{~Pa}^{-1}\right)$ & $\Delta h_{m}\left(\mathrm{Jg}^{-1}\right)$ & $T_{m}\left({ }^{\circ} \mathrm{C}\right)$ \\
\hline $0 \%$ & $31.6 \pm 0.9^{\mathrm{a}}$ & $12.6 \pm 0.5^{\mathrm{a}}$ & $0.094 \pm 0.002^{\mathrm{a}}$ & $6.02 \pm 0.40^{\mathrm{a}}$ & 59.8 & 192.4 \\
\hline $0.1 \%$ & $29.1 \pm 1.5^{\mathrm{a}}$ & $11.8 \pm 0.2^{\mathrm{ab}}$ & $0.115 \pm 0.002^{\mathrm{b}}$ & $6.71 \pm 0.27^{\mathrm{a}}$ & 50.1 & 194.5 \\
\hline $0.2 \%$ & $31.5 \pm 2.3^{\mathrm{a}}$ & $11.4 \pm 0.2^{b}$ & $0.120 \pm 0.003^{b}$ & $7.38 \pm 0.03^{b}$ & 34.6 & 202.5 \\
\hline
\end{tabular}

${ }^{\mathrm{a}-\mathrm{b}}$ Different superscripts within the same column indicate significant differences among formulations $(p<0.05)$.

to $\mathrm{C}-\mathrm{O}-\mathrm{H}$ group when $\alpha$-tocopherol was added to the film can be related to the amount of the water molecules absorbed in the chitosan film (Kačuráková and Mathlouthi, 1996). However, the chitosan films' solubility was not affected by the incorporation of $\alpha$ tocopherol $(p>0.05)$. Ojagh, Rezaei, Razavi, and Hosseini (2010) reported that cinnamon essential oil decreased moisture content and solubility in water of chitosan-based films.

\subsection{Water vapor permeability (WVP) measurement}

The water vapor permeability is the most extensively studied property of edible films mainly because of the importance of water in deteriorative reactions in foods. The presence and increase of $\alpha$-tocopherol concentration leads to the increase of WVP values (Table 4). A great number of factors can affect the WVP of chitosan films as e.g. film thickness, water sensitivity and crystallinity.

The increase of $\alpha$-tocopherol concentration results in increases of the values of thickness (Table 4), but also can affect the hydrophilic-hydrophobic behavior of the chitosan-based film. Byun et al. (2010) reported that addition of hydrophobic $\alpha$-tocopherol to polylactic acid films improves water vapor barrier properties. However, despite the hydrophobic character of $\alpha$-tocopherol, WVP values increased when $\alpha$-tocopherol was added to chitosan films. This could be due to the effect of $\alpha$-tocopherol addition over the cohesion forces of the chitosan network, as observed in the mechanical properties results (Section 3.5.); this would improve water vapor transport through the film matrix. Similar results were found by Bonilla, Atarés, Vargas, and Chiralt (2011) in chitosanbased films containing essential oils (basil and thyme). It was also noticed that the presence of $\alpha$-tocopherol originated less crystalline films (Table 4), leading to an increase of WVP. This hypothesis was advanced since it is well known that polymers with high crystallinity usually are less permeable due their ordered structure, and that the mass transfer of a gas in a semi-crystalline polymer is

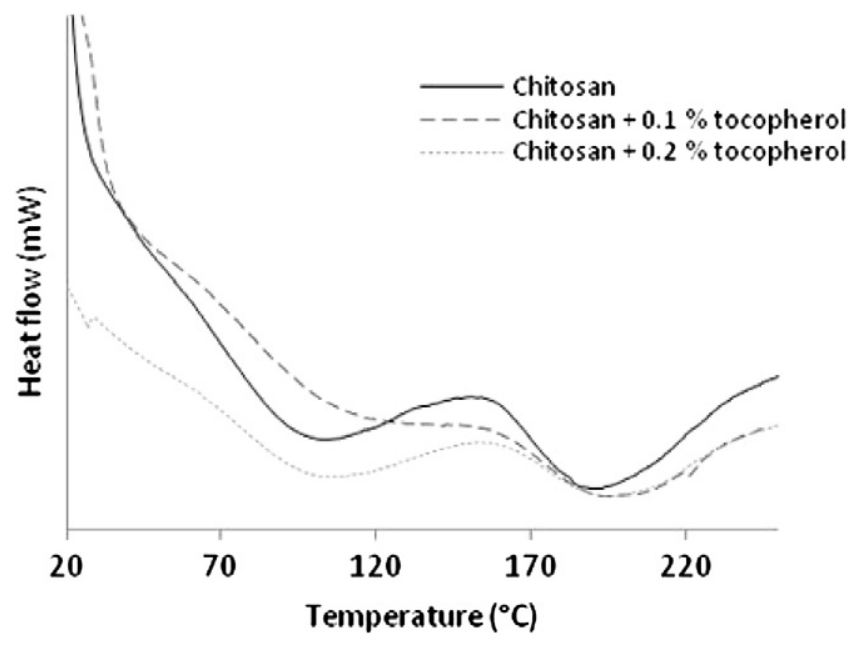

Fig. 5. DSC thermograms of chitosan films with $\alpha$-tocopherol. primarily a function of the amorphous phase (Sperling, 2006, chap. 6; Miller \& Krochta, 1997).

\subsection{Mechanical properties - TS and EB}

Mechanical properties reflect the film's ability to protect the integrity of foods. Fig. 6 shows the effect of the increase of $\alpha$-tocopherol concentration on the values of TS and EB of chitosanbased films. Chitosan films present values of $34.06 \mathrm{MPa}$ and $53.85 \%$ for $T S$ and $E B$, respectively. These values are higher than those reported by Ojagh et al. (2010) $(T S=10.97 \mathrm{MPa}$ and $E B=24.73 \%)$ and Souza et al. (2010) $(T S=13 \mathrm{MPa}$ and $E B=16 \%)$. This could be due to several factors such as chitosan composition and source, plasticizer presence, film preparation and storage (Sánchez-González et al., 2009). It was noted that the $\alpha$-tocopherol incorporation significantly decreased the TS and $E B$ of the chitosan films. A similar trend was reported by Jongjareonrak et al. (2008) on fish skin gelatin films incorporated with $\alpha$-tocopherol.

In the current work, the addition of hydrophobic $\alpha$-tocopherol inside chitosan film induces the development of structural discontinuities, producing a film structure with less chain mobility, and consequently, with less flexibility and resistance to fracture (Sánchez-González et al., 2009). Srinivasa, Ramesh, and Tharanathan (2007) reported that the incorporation of saturated fatty acids into chitosan films decreased TS and EB. Similar behavior was observed when $\alpha$-tocopherol was added to chitosan film. Generally, oil addition to polysaccharide films decrease $T S$ and $E B$ values, once lipids are not capable to form continuous and cohesive matrices (Péroval, Debeaufort, Despre, \& Voilley, 2002). Also, the water content of the films can affect their mechanical properties. As previously mentioned, the increase of $\alpha$-tocopherol concentration on the chitosan films decreased the water content (Table 4). A lower water content is expected to decrease film plasticity, because water also acts like a plasticizer (Rivero et al., 2010).

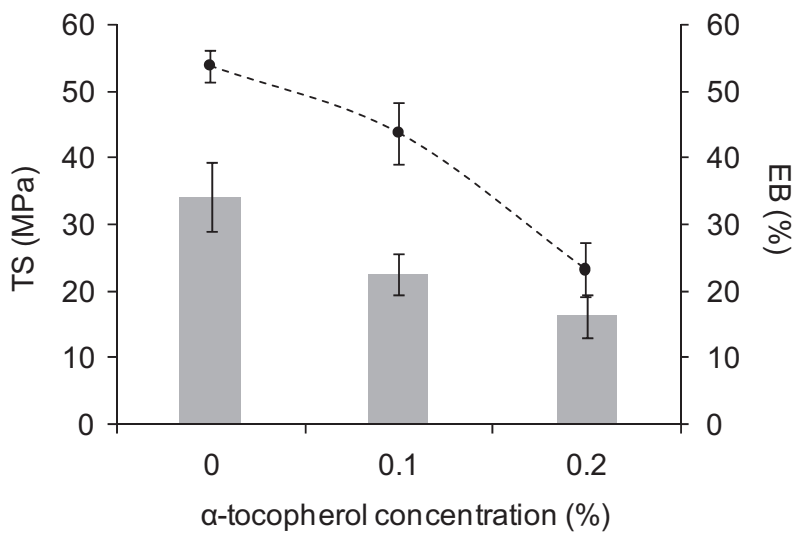

Fig. 6. Tensile strength $(T S)$ and elongation-at-break $(E B)$ of chitosan films for increasing $\alpha$-tocopherol concentrations. TS and EB are represented by columns and dots, respectively. 
Table 5

Color parameters, $L^{*}, a^{*}$ and $b^{*}$, opacity and DPPH radical scavenging activity of the chitosan films for increasing concentrations of $\alpha$-tocopherol.

\begin{tabular}{|c|c|c|c|c|c|}
\hline$\alpha$-Tocopherol & $L^{*}$ & $a^{*}$ & $b^{*}$ & Opacity (\%) & DPPH radical scavenging activity/100 mg of film (\%) \\
\hline $0 \%$ & $95.41 \pm 0.47^{\mathrm{a}}$ & $3.54 \pm 0.35^{\mathrm{a}}$ & $5.94 \pm 1.89^{\mathrm{a}}$ & $4.74 \pm 0.49^{\mathrm{a}}$ & $10.69 \pm 1.00^{\mathrm{a}}$ \\
\hline $0.1 \%$ & $92.57 \pm 1.00^{\mathrm{b}}$ & $1.66 \pm 0.28^{\mathrm{b}}$ & $15.06 \pm 3.04^{\mathrm{b}}$ & $6.71 \pm 0.80^{\mathrm{b}}$ & $97.42 \pm 0.71^{\mathrm{b}}$ \\
\hline $0.2 \%$ & $92.34 \pm 0.83^{\mathrm{b}}$ & $1.58 \pm 0.29^{b}$ & $15.73 \pm 2.54^{\mathrm{b}}$ & $7.83 \pm 0.32^{\mathrm{b}}$ & $97.71 \pm 0.22^{\mathrm{b}}$ \\
\hline
\end{tabular}

${ }^{\mathrm{a}-\mathrm{b}}$ Different superscripts within the same column indicate significant differences among formulations $(p<0.05)$.

\subsection{Optical properties - color, opacity and light transmittance of the films}

Exposure to visible and ultraviolet light causes oxidative deterioration of packaged foods, leading to nutrient losses, discoloration and off-flavors. Table 5 shows the behavior of the color parameters and opacity of chitosan-based films after incorporation of $\alpha$-tocopherol. The incorporation of $\alpha$-tocopherol on chitosanbased films leads to a decrease of the $L^{*}$ and $a^{*}$ parameters, indicating a decrease of the lightness and an increase of the greenness of the film. The increase of $b^{*}$ indicates the intensification of the yellowness of the chitosan film. However, there were no significant differences in $L^{*}$ between $0.1 \%$ and $0.2 \% \alpha$-tocopherol-chitosan films $(p>0.05)$. This result shows that the addition of $\alpha$-tocopherol had a significant effect on $a^{*}$ and $b^{*}$ parameters of chitosan films. As shown in Table 5, chitosan films without $\alpha$-tocopherol presented the lower level of opacity $(p<0.05)$ when compared with films containing $\alpha$-tocopherol. These results suggested that the addition of $\alpha$-tocopherol decreases the transparency of the chitosan. Siripatrawan and Harte (2010) also observed that aqueous green tea extract incorporated in chitosan films decreases film lightness and increases the opacity.

Chitosan films with and without $\alpha$-tocopherol presented different light transmission profiles in visible $(350-700 \mathrm{~nm})$ and UV (250-350 nm) ranges (Fig. 7). An increase of $\alpha$-tocopherol concentration led to an improvement of the film barrier to UV and visible light. $0.2 \% \alpha$-tocopherol-chitosan films presented the lowest level of transmittance in the UV range (especially between 250 and $300 \mathrm{~nm}$ ). As a result, the low level of transmission in the UV range can make $\alpha$-tocopherol-chitosan-based films an excellent barrier to prevent UV light-induced lipid oxidation when applied in food systems. Wessling, Nielsen, and Leufvén (2000) also showed that low-density polyethylene (LDPE) film containing $\alpha$-tocopherol offered UV protection compared to film without $\alpha$-tocopherol.

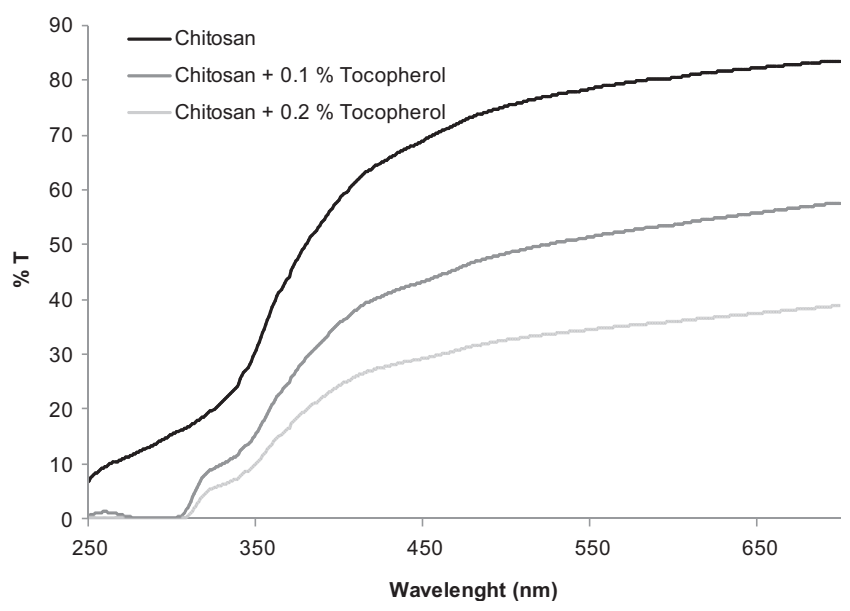

Fig. 7. Light transmission characteristics for chitosan films with $\alpha$-tocopherol.

\subsection{DPPH radical scavenging assay}

DPPH radical has been widely used to test the ability of compounds as free radical scavengers or hydrogen donors in order to evaluate the antioxidant activity. DPPH tests were conducted to evaluate whether the $\alpha$-tocopherol retained its antioxidant capacity during incorporation in chitosan films. The radical scavenging activity of chitosan films with and without incorporated $\alpha$-tocopherol was determined and is presented in Table 5. Chitosan films showed radical scavenging activity of $10.69 \%$ on DPPH, which may be mainly attributed to the capacity of residual free amino groups of chitosan to react with free radicals forming stable macromolecular radicals and ammonium groups (Xie, Xu, \& Liu, 2001). Films with $\alpha$-tocopherol exhibited a higher level of radical scavenging activity with values of 97.42 and $97.71 \%$ for 0.1 and $0.2 \%$ of $\alpha$-tocopherol containing films, respectively. However, no significant difference between the two $\alpha$-tocopherol concentrations incorporated in the films was observed. The activity values achieved for $\alpha$-tocopherol-chitosan films in this study were of the same order of magnitude as those reported in literature (Byun et al., 2010). According to these authors, the antioxidant activity of polylactic acid film with BHT and polyethylene glycol increased from $14.2 \%$ to $90.43 \%$ when $\alpha$-tocopherol was added to the film.

In the present work, the increased antioxidant activity is due to the effectiveness of the $\alpha$-tocopherol incorporated within chitosan films. The interaction between $\alpha$-tocopherol and chitosan molecules could influence the total radical scavenging activity of the film, in a similar way as that suggested by Siripatrawan and Harte (2010), who reported that green tea extract incorporation in chitosan films enhanced antioxidant activity possibly due to hydrogen and covalent bonding between polyphenols and chitosan.

\section{Conclusion}

The present work shows that $\alpha$-tocopherol can be added to a chitosan film matrix, imparting a good antioxidant activity. This incorporation influenced chemical, mechanical, barrier and color properties of the chitosan films: an increase of $\alpha$-tocopherol concentration promoted a decrease of water content and led to an increase of $W V P$, a reduction of $T S$ and $E B$ values, and an increase of chitosan-based films' opacity. The incorporation of $\alpha$-tocopherol may also be used to protect foods from UV light-induced degradation. Therefore, these films can be promising alternatives to synthetic materials and as a vehicle for functional compounds, possibly contributing to food preservation and shelf-life extension.

\section{Acknowledgments}

J. T. Martins and M. A. Cerqueira gratefully acknowledge the Fundação para a Ciência e Tecnologia (FCT, Portugal) for their fellowships (SFRH/BD/32566/2006 and SFRH/BPD/72753/2010, respectively).

\section{References}

Aider. (2010). Chitosan application for active bio-based films production and potential in the food industry: review. LWT - Food Science and Technology, 43, $837-842$. 
Bonilla, J., Atarés, L., Vargas, M., \& Chiralt, A. (2011). Effect of essential oils and homogenization conditions on properties of chitosan based films. Food Hydrocolloids, 26, 9-16.

Bramley, P. M., Elmadfa, I., Kafatos, A., Kelly, F. J., Manios, Y., Roxborough, H. E., et al (2000). Review - vitamin E. Journal of the Science of Food and Agriculture, 80, 913-938.

Bu, X., Wang, L., Ma, W., Yu, X., McDowell, W. H., \& Ruan, H. (2010). Spectroscopic characterization of hot-water extractable organic matter from soils under four different vegetation types along an elevation gradient in the Wuyi Mountains. Geoderma, 159, 139-146.

Byun, Y., Kim, Y. T., \& Whiteside, S. (2010). Characterization of an antioxidant polylactic acid (PLA) film prepared with a-tocopherol, BHT and polyethylene glycol using film cast extruder. Journal of Food Engineering, 100, 239-244.

Cao, S., Shi, Y., \& Chen, G. (1998). Blend of chitosan acetate salt with poly(N-vinyl-2pyrrolidone): interaction between chain-chain. Polymer Bulletin, 41, 553-559.

Casariego, A., Souza, B. W. S., Cerqueira, M. A., Cruz, L., Díaz, R., \& Vicente, A. A. (2009). Chitosan/clay films' properties as affected by biopolymer and clay micro/nanoparticles' concentrations. Food Hydrocolloids, 23, 1895-1902.

Debeaufort, F., \& Voilley, A. (2009). Characterization of starch and composite edible films and coatings. In M. E. Embuscado, \& K. C. Huber (Eds.), Edible films and coatings for food applications, Vol. 3 (pp. 135-168). Berlin: Springer.

Dutta, P. K., Tripathi, S., Mehrotra, G. K., \& Dutta, J. (2009). Perspectives for chitosan based antimicrobial films in food applications. Food Chemistry, 114, 1173-1182.

Fabra, M. J., Talens, P., \& Chiralt, A. (2010). Water sorption isotherms and phase transitions of sodium caseinate-lipid films as affected by lipid interactions. Food Hydrocolloids, 24, 384-391.

Ferreira, C. O., Nunes, C. A., Delgadillo, I., \& Lopes-da-Silva, J. A. (2009). Characterization of chitosan-whey protein films at acid pH. Food Research International, 42, 807-813.

García, M. A., Pinotti, A., Martino, M. N., \& Zaritzky, N. E. (2009). Characterization of starch and composite edible films and coatings. In M. E. Embuscado, \& K. C. Huber (Eds.), Edible films and coatings for food applications, Vol. 3 (pp. 169-209). Berlin: Springer.

Gnanasambadam, R., Hettiarachchy, N. S. \& Coleman, M. (1997). Mechanical and barrier properties of rice bran films. Journal of Food Science, 62(2), 395-398.

Guillard, V., Broyart, B., Bonazzi, C., Guilbert, S., \& Gontard, N. (2003). Preventing moisture transfer in a composite food using edible films: experimental and mathematical study. Journal of Food Science, 68(7), 2267-2277.

Jamróz, M. E., Jarosz, M., Witowska-Jarosz, J., Bednarek, E., Tecza, W., Jamróz, M. H., et al. (2007). Mono-, di-, and tri-tert-butyl ethers of glycerol. A molecular spectroscopic study. Spectrochimica Acta Part A, 67, 980-988.

Jongjareonrak, A., Benjakul, S., Visessanguan, W., \& Tanaka, M. (2008). Antioxidative activity and properties of fish skin gelatin films incorporated with BHT and $\alpha$-tocopherol. Food Hydrocolloids, 22, 449-458.

Kačuráková, M., \& Mathlouthi, M. (1996). FTIR and laser-Raman spectra of oligosaccharides in water: characterization of the glycosidic bond. Carbohydrate Research, 284, 145-157.

Kamal-Eldin, A., \& Andersson, R. (1997). A multivariate study of the correlation between tocopherol content and fatty acid composition in vegetable oils. Journal of the American Oil Chemists' Society, 74(4), 375-380.

Khwaldia, K., Arab-Tehrany, E., \& Desobry, S. (2010). Biopolymer coatings on paper packaging materials. Comprehensive Reviews in Food Science and Food Safety, 9 , $82-91$

Koontz, J. L., Marcy, J. E., O’Keefe, S. F., Duncan, S. E., Long, T. E., \& Moffitt, R. D. (2010). Polymer processing and characterization of LLDPE films loaded with $\alpha$-tocopherol, quercetin, and their cyclodextrin inclusion complexes. Journal of Applied Polymer Science, 117, 2299-2309.

Kumar, M. N. V. R. (2000). A review of chitin and chitosan applications. Reactive and Functional Polymers, 46(1), 1-27.

Lee, D. S. (2005). Packaging containing natural antimicrobial or antioxidative agents. In J. Han (Ed.), Innovations in food packaging (pp. 108-119). Elsevier Science \& Technology Books.

Lin, D., \& Zhao, Y. (2007). Innovations in the development and application of edible coatings for fresh and minimally processed fruits and vegetables. Comprehensive Reviews in Food Science and Food Safety, 6(3), 60-75.

Luo, Y., Zhang, B., Whent, M., Yu, L., \& Wang, K. (2011). Preparation and characterization of zein/chitosan complex for encapsulation of $\alpha$-tocopherol, and its in vitro controlled release study. Colloids and Surfaces B: Biointerfaces, 85(2), 145-152.

Mart, H., Sökmen, T., \& Yürük, H. (2006). The synthesis and thermal properties of oligo-3-hydroxybenzaldehyde synthesized by oxidative polycondensation. Journal of Applied Polymer Science, 101, 892-897.

McHugh, T. H., Avena-Bustillos, R., \& Krochta, J. M. (1993). Hydrophilic edible film: modified procedure for water vapor permeability and explanation of thickness effects. Journal of Food Science, 58, 899-903.

Miller, K. S., \& Krochta, J. M. (1997). Oxygen and aroma barrier properties of edible films: a review. Trends in Food Science and Technology, 8, 228-237.

Ning, W., Jiugao, Y., Xiaofei, M., \& Ying, W. (2007). The influence of citric acid on the properties of thermoplastic starch/linear low-density polyethylene blends. Carbohydrate Polymers, 67, 446-453.
Ojagh, S. M., Rezaei, M., Razavi, S. H., \& Hosseini, S. M. H. (2010). Development and evaluation of a novel biodegradable film made from chitosan and cinnamon essential oil with low affinity toward water. Food Chemistry, 122(1), 161-166.

Park, S., \& Zhao, Y. (2004). Incorporation of a high concentration of mineral or vitamin into chitosan-based films. Journal of Agricultural and Food Chemistry, 52, 1933-1939.

Pawlak, A., \& Mucha, M. (2003). Thermogravimetric and FTIR studies of chitosan blends. Thermochimica Acta, 396, 153-166.

Peesan, M., Supaphol, P., \& Rujiravanit, R. (2005). Preparation and characterization of hexanoyl chitosan/polylactide blend films. Carbohydrate Polymers, 60(3), 343-350.

Pelissari, F. M., Grossmann, M. V. E., Yamashita, F., \& Pineda, E. A. G. (2009). Antimicrobial, mechanical, and barrier properties of cassava starch-chitosan films incorporated with oregano essential oil. Journal of Agricultural and Food Chemistry, 57, 7499-7504.

Péroval, C., Debeaufort, F., Despre, D., \& Voilley, A. (2002). Edible arabinoxylanbased films. 1. Effects of lipid type on water vapor permeability, film structure, and other physical characteristics. Journal of Agricultural and Food Chemistry, 50, 3977-3983.

Prado, A. G. S., Santos, A. L. F., Pedroso, C. P., Carvalho, T. O., Braga, L. R., \& Evangelista, S. M. (2011). Vitamin A and vitamin E interaction behavior on chitosan microspheres. Journal of Thermal Analysis and Calorimetry, doi:10.1007/ s10973-011-1418-8.

Quijada-Garrido, I., Iglesias-González, V., Mazón-Arechederra, J. M., \& BarralesRienda, J. M. (2007). The role played by the interactions of small molecules with chitosan and their transition temperatures. Glass-forming liquids: 1,2,3propantriol (glycerol). Carbohydrate Polymers, 68, 173-186.

Rao, M. S., Kanatt, S. R., Chawla, S. P., \& Sharma, A. (2010). Chitosan and guar gum composite films: preparation, physical, mechanical and antimicrobial properties. Carbohydrate Polymers, 82, 1243-1247.

Rivero, S., García, M. A., \& Pinnoti, A. (2010). Correlations between structural, barrier, thermal and mechanical properties of plasticized gelatin films. Innovative Food Science \& Emerging Technologies, 11(2), 369-375.

Sánchez-González, L, Vargas, M., González-Martínez, C., Chiralt, A., \& Cháfer, M. (2009). Characterization of edible films based on hydroxypropylmethylcellulose and tea tree essential oil. Food Hydrocolloids, 23(8), 2102-2109.

Silva, S. D., Rosa, N. F., Ferreira, A. E., Boas, L. V., \& Bronze, M. R. (2009). Rapid determination of $\alpha$-tocopherol in vegetable oils by Fourier transform infrared spectroscopy. Food Analytical Methods, 2, 120-127.

Siripatrawan, U., \& Harte, B. R. (2010). Physical properties and antioxidant activity of an active film from chitosan incorporated with green tea extract. Food Hydrocolloids, 24, 770-775.

Souza, B. W. S., Cerqueira, M. A., Martins, J. T., Casariego, A., Teixeira, J. A., \& Vicente, A. A. (2010). Influence of electric fields on the structure of chitosan edible coatings. Food Hydrocolloids, 24, 330-335.

Sperling, L. H. (2006). Introduction to physical polymer science (4th ed.). New Jersey: John Wiley \& Sons, Inc.

Srinivasa, P. C., Ramesh, M. N., \& Tharanathan, R. N. (2007). Effect of plasticizers and fatty acids on mechanical and permeability characteristics of chitosan films. Food Hydrocolloids, 21, 1113-1122.

Strandberg, C., \& Albertsson, A.-C. (2006). Improvement of $\alpha$-tocopherols long-term efficiency by modeling its heterogeneous natural environment in polyethylene. Journal of Polymer Science Part A: Polymer Chemistry, 44(5), 1660-1666.

Sun, S., \& Wang, A. (2006). Adsorption properties and mechanism of cross-linked carboxymethyl-chitosan resin with $\mathrm{Zn}(\mathrm{II})$ as template ion. Reactive \& Functional Polymers, 66, 819-826.

Vlachos, N., Skopelitis, Y., Psaroudaki, M., Konstantinidou, V., Chatzilazarou, A., \& Tegou, E. (2006). Applications of Fourier transform-infrared spectroscopy to edible oils. Analytica Chimica Acta, 573-574, 459-465.

Wessling, C., Nielsen, T., \& Leufvén, A. (2000). The influence of $\alpha$-tocopherol concentration on the stability of linoleic acid and the properties of low-density polyethylene. Packaging Technology and Science, 13, 19-28.

Wessling, C., Nielsen, T., Leufvén, A., \& Jägerstad, M. (1999). Retention of $\alpha$-tocopherol in low-density polyethylene (LDPE) and polypropylene (PP) in contact with foodstuffs and food-simulating liquids. Journal of the Science of Food and Agriculture, 79, 1635-1641.

Xie, W., Xu, P., \& Liu, Q. (2001). Antioxidant activity of water-soluble chitosan derivatives. Bioorganic \& Medicinal Chemistry Letters, 11, 1699-1701.

Xu, Y. X., Kim, K. M., Hanna, M. A., \& Nag, D. (2005). Chitosan-starch composite film: preparation and characterization. Industrial Crops and Products, 21, 185-192.

Yoshida, C. M. P., Junior, E. N. O., \& Franco, T. T. (2009). Chitosan tailor-made films: the effects of additives on barrier and mechanical properties. Packaging Technology Science, 22, 161-170.

Ziani, K., Oses, J., Coma, V., \& Maté, J. I. (2008). Effect of the presence of glycerol and Tween 20 on the chemical and physical properties of films based on chitosan with different degree of deacetylation. LWT - Food Science and Technology, 41(10), 2159-2165.

Zohuriaan, M. J., \& Shokrolahi, F. (2004). Thermal studies on natural and modified gums. Polymer Testing, 23, 575-579. 